\title{
Motility of copepod nauplii and implications for food encounter
}

\author{
Josefin Titelman $^{1,2,3, *}$, Thomas Kiørboe ${ }^{1}$ \\ ${ }^{1}$ Danish Institute for Fisheries Research, Department of Marine Ecology and Aquaculture, Kavalergården 6, \\ 2920 Charlottenlund, Denmark \\ ${ }^{2}$ Göteborg University, Department of Marine Ecology, Kristineberg Marine Research Station, 45034 Fiskebäckskil, Sweden \\ ${ }^{3}$ Present address: Plymouth Marine Laboratory, Prospect Place, The Hoe, Plymouth PL1 3DH, United Kingdom
}

\begin{abstract}
Velocity differences drive all encounter processes. Therefore, knowledge of both prey and predator motility are essential in order to understand feeding behavior and predict food acquisition rates. Here, we describe and quantify the motility behavior of young and old naupliar stages of 6 copepods (Centropages typicus, Calanus helgolandicus, Temora longicornis, Acartia tonsa, Eurytemora affinis and Euterpina acutifrons). Behaviors of individual nauplii were divided into sequences of sinking, swimming and jumping events. Motility behavior is both stage- and species-specific in terms of appearance of tracks, speeds, durations and frequencies of events as well as time budgets. Motility mode often changes drastically during naupliar ontogeny. Crudely, nauplii can be divided into those moving with a jump-sink type of motility of various frequencies $\left(1 \mathrm{~min}^{-1}\right.$ to $\left.3 \mathrm{~s}^{-1}\right)$ and those swimming with a smoother glide of varying continuity. We apply observed time budgets and behavior-specific speeds in simple models to examine mechanisms of food encounter. The motility of all nauplii may account for clearance rates reported in the literature, but through different mechanisms. Smoothly swimming nauplii encounter food by scavenging, which also allows for some food capture inefficiency. Jump-sink types rely on motile food. We demonstrate how diffusivity of motile prey may account for observed clearance rates for jump-sink types, which seem to employ 2 strategies. Infrequent jumping as observed in many cyclopoids is sufficient to prevent prey diffusion from reaching steady state rates, which are too low to account for observed clearance rates reported in the literature. Frequent jumpers (e.g. Acartia tonsa) jump at a frequency close to the optimum required to maximize the use of prey motility and to avoid local food depletion.
\end{abstract}

KEY WORDS: Nauplii · Copepod $\cdot$ Motility $\cdot$ Behavior $\cdot$ Food encounter $\cdot$ Clearance rate $\cdot$ Volume encounter $\cdot$ Predator prey interaction $\cdot 3 \mathrm{D}$

\section{INTRODUCTION}

Encounter is the ultimate prerequisite for any predator-prey interaction. In turn, encounters are driven by velocity differences arising from motility of the predator, the prey or both. Most organisms act simultaneously as both predator and prey, and thus, face tradeoffs related to eating and growing on one hand and avoiding predation mortality on the other. Because survival requires fulfillment of both tasks, it is expected that motility strategies reflect adaptations to restricting encounters with predators, while enhancing encounter with food. Understanding feeding behavior and pre- dicting food acquisition rates therefore requires description and quantification of motility patterns of both predator and prey. Here, we examine motility strategies in the light of food acquisition using copepod nauplii as model organisms. In our companion paper (Titelman \& Kiørboe 2003 this issue), we consider the costs of the various motility patterns in terms of predation risk.

Nauplii, i.e. the first 6 developmental stages in the copepod life cycle, are numerically the most abundant multicellular zooplankters in marine systems. Yet, quantitative studies of naupliar behavior are rare (e.g. Buskey et al. 1993, van Duren \& Videler 1995, Paffenhöfer et al. 1996), and the mechanisms involved in their 
encounters with both predator and prey are poorly understood. Nauplii of many cyclopoid copepods remain virtually motionless while sinking slowly and relocate only occasionally with fast jumps (Gauld 1958, Björnberg 1972, Gerritsen 1978, Paffenhöfer et al. 1996), while calanoid nauplii exhibit a more diverse range of motility behaviors (Storch 1928, Gauld 1958, Björnberg 1972, Buskey et al. 1993, van Duren \& Videler 1995, Paffenhöfer et al. 1996). The mode of motility, i.e. swimming, sinking and jumping, implies differences in velocity that, in combination with frequency and duration of these events, govern zooplankton food encounter rates (van Duren \& Videler 1995). Some plankters also create a feeding current that increases food encounter (Paffenhöfer \& Lewis 1989). Although different motility modes have different implications for the encounter with both food and predators, most studies have not resolved activity into different behaviors, but rather considered average velocities (Gerritsen 1978, Landry \& Fagerness 1988, Buskey et al. 1993, Buskey 1994). Generally, data that can be used to understand how nauplii and other small zooplankters encounter food or predators are limited.

Here, the behavior of 6 species and various stages of copepod nauplii is described and quantified in detail from video observations made in 3 dimensions (3D). We show 3D motion tracks and discuss the observed motility patterns mainly in light of their implications for food encounter.

\section{MATERIALS AND METHODS}

Cultures. Continuous copepod cultures were established from 50 to 500 copepodids per species. Copepods were collected in Gullmarsfjorden, Sweden (Centropages typicus, Calanus spp.), Tvärminne, Finland (Eurytemora affinis) and in the Mediterranean waters of Spain (Euterpina acutifrons). Acartia tonsa came from our previously established laboratory culture (Støttrup et al. 1986) as did Temora longicornis (Titelman 2001). Copepods were kept in 1 to 2001 containers at room temperature and ambient light, and were fed a mixture of Rhodomonas baltica (equivalent spherical diameter, ESD $\sim 7 \mu \mathrm{m}$ ), Thalassiossira weissflogii (ESD $\sim 14 \mu \mathrm{m}$ ) and Heterocapsa triquetera (ESD 15 $\mu \mathrm{m}$ ) ad libitum. For the free-spawning species, artificial cohorts of nauplii were obtained by collecting eggs from the cultures and allowing the eggs to hatch for 12 to $25 \mathrm{~h}$, whereupon unhatched eggs were removed. For the egg-carrying species (E. acutifrons and E. affinis), artificial cohorts were obtained by isolating egg-bearing females and using all nauplii hatched within $24 \mathrm{~h}$.

Video set-up and filming. Behavioral observations were made in a temperature controlled room $\left(18^{\circ} \mathrm{C}\right)$ in
0.25 or 51 aquaria. Two CCD cameras viewed the aquarium from right angles. The cameras were equipped with macro lenses (Nikkor AF Micro $105 \mathrm{~mm}$ ) and were connected to a synchronizer, a mixer, a time-date generator (Panasonic WJ 180) and a VCR (Panasonic NV-FS200 HQ). Collimated light from 2 IR diodes provided the only light source.

Nauplii were gently washed on a $40 \mu \mathrm{m}$ mesh to remove food particles and transferred to $0.2 \mu \mathrm{m}$ filtered seawater. Naupliar concentrations during filming were 1 to 5 nauplii $\mathrm{ml}^{-1}$, and the volume of the aquarium was chosen based on the number of available nauplii. The aquarium was covered by a lid and submerged in a larger aquarium in order to stabilize temperature and limit convection. Filming lasted for 2 to $8 \mathrm{~h}$, and was repeated with additional aliquots of nauplii when necessary (i.e. when an insufficient number of encounters or when convection was evident). Although we often considered nauplii filmed in one aquarium only, we ensured that the behavior was representative of the species and stage group by qualitatively observing the general behavior of the same taxon in other aquaria and also in conjunction with experiments of detection abilities (Titelman \& Kiørboe 2003).

Between 5 and 40 swim tracks were considered for each stage and species group. Each track lasted for as long as the nauplii remained in the field of view of both cameras. Magnifications varied depending on size and concentration of nauplii, but were always sufficient to adequately resolve sinking speeds. Hence, duration of individual observations varied, and swim tracks ranged between $1 \mathrm{~s}$ and $3 \mathrm{~min}$ in duration. Samples were preserved in formalin for stage and size determination. (Table 1).

Image analysis and characterization of motility. Selected video clips were captured (Moto DV, 25 frames $\mathrm{s}^{-1}$ ) as QuickTime TM movies, after which swim paths were automatically analyzed using LabTrack software (DiMedia, Kvistgård, Denmark). With this software, the $x, z$ and the $y, z$ planes are tracked independently of one another and subsequently combined into a $3 \mathrm{D}$ picture. The program allows setting of thresholds for size, minimum track length, minimum velocity and contrast, ensuring that only the target particles (i.e. nauplii) are tracked. The time step was 0.04 to $0.12 \mathrm{~s}$, usually $0.04 \mathrm{~s}$, depending on the motility of the nauplii. Output sequences of $x, y, z$ coordinates were subsequently used to characterize the motility.

Time budgets, velocities and frequencies of sinking, swimming and jumping behavior were determined using a MatLab code, which divided each track into a series of sink and move events. Move events were subsequently divided into swim and jump events. Criteria and thresholds for defining types of events were 
Table 1. Size and stage distributions measured for 20 to 30 individuals per filming. The stage column shows the 2 most common stages with the more abundant one underlined. The percentage column shows the percentage contribution of the 2 dominant stages and that of the dominant one in parenthesis. Lengths are total body lengths excluding caudal armature and are reported as mean \pm SD considering all measured nauplii. For early Centropages typcicus and late Euterpina acutifrons, several filmings were conducted and these data are pooled, here as well as in the results

\begin{tabular}{|c|c|c|c|c|}
\hline Species & $\begin{array}{l}\text { Nominal } \\
\text { group }\end{array}$ & $\begin{array}{l}\text { Nauplius } \\
\text { stage }\end{array}$ & $\%$ & $\begin{array}{c}\text { Length } \pm \text { SD } \\
(\mu \mathrm{m})\end{array}$ \\
\hline Acartia tonsa & $\begin{array}{l}\text { Early } \\
\text { Late }\end{array}$ & $\stackrel{\text { I }}{\text { IV }-\mathrm{V}}$ & $\begin{array}{r}100(\underline{100}) \\
90(\underline{53})\end{array}$ & $\begin{array}{l}118 \pm 4 \\
229 \pm 30\end{array}$ \\
\hline Calanus helgolandicus & $\begin{array}{l}\text { Early } \\
\text { Late }\end{array}$ & $\begin{array}{l}\text { I-II } \\
\text { IV- } \underline{V}\end{array}$ & $\begin{array}{r}100(\underline{83}) \\
93(\underline{63})\end{array}$ & $\begin{array}{l}231 \pm 14 \\
553 \pm 54\end{array}$ \\
\hline Centropages typicus & $\begin{array}{l}\text { Early } \\
\text { Late }\end{array}$ & $\begin{array}{l}\text { I-II } \\
\text { IV-V }\end{array}$ & $100(\underline{60})$ & $\begin{array}{l}132 \pm 16 \\
225 \pm 33\end{array}$ \\
\hline Eurytemora affinis & $\begin{array}{l}\text { Early } \\
\text { Late }\end{array}$ & $\begin{array}{l}\text { I-II } \\
\text { IV-V }\end{array}$ & $\begin{array}{r}100(\underline{67}) \\
73(\underline{60})\end{array}$ & $\begin{array}{l}132 \pm 11 \\
202 \pm 27\end{array}$ \\
\hline Euterpina acutifrons & $\begin{array}{l}\text { Early } \\
\text { Late }\end{array}$ & $\begin{array}{l}\text { I-II } \\
\text { IV- } \underline{V}\end{array}$ & $\begin{array}{l}93(\underline{83}) \\
93(\underline{71})\end{array}$ & $\begin{array}{l}112 \pm 15 \\
200 \pm 27\end{array}$ \\
\hline Temora longicornis & $\begin{array}{l}\text { Early } \\
\text { Late }\end{array}$ & $\begin{array}{l}\underline{\mathrm{I}}-\mathrm{II} \\
\underline{\mathrm{V}}-\mathrm{VI}\end{array}$ & $\begin{array}{l}87(\underline{80}) \\
73(\underline{47})\end{array}$ & $\begin{array}{l}138 \pm 36 \\
308 \pm 36\end{array}$ \\
\hline
\end{tabular}

adjusted depending on naupliar behavior and track resolution.

For jump speeds, the maximum speed within each event was calculated. For sink events, only start and stop coordinates were used to calculate the speed, and only sink events longer than 5 frames were considered. Swim speeds were calculated after smoothing the position data by computing a running average position of 2 consecutive frames, after which an average swim speed was obtained for each event. For each track, the average speeds of all events of the respective types were then calculated. Finally, mean speeds were computed by averaging over all individuals. We weighted each individual equally regardless of track length, assuming that behavior exhibited on stage was representative of the behavior outside the field of view.

Although it is possible that the same individual was filmed twice, it is unlikely at the naupliar abundances used, and we assume that at this low naupliar density naupliar tracks are independent of other nauplii within the container. That is, we assume that tracks are statistically independent of one another. Time budgets and sink/move frequencies were also determined manually for 9 to 10 tracks per group. The time step was always $0.04 \mathrm{~s}$.

\section{RESULTS}

\section{General observations}

The various species and stages behaved strikingly differently, differing from one another in event frequencies, event durations, velocities, and overall trail patterns (Fig. 1, Table 2). Within groups variability was generally low and swim tracks looked similar. Based on behavior,
Fig. 1. Schematic representation of motility based on mean frequencies, durations and speeds of events (Table 2). The total length of the bars represents $1 \mathrm{~min}$. White bands are periods of sinking and gray to black bands of moving. The width of the band is proportional to the duration of the event, while the gray scale represents the speed of the event. Speeds were converted to body lengths $\mathrm{s}^{-1} \mathrm{using}$ sizes from Table 1

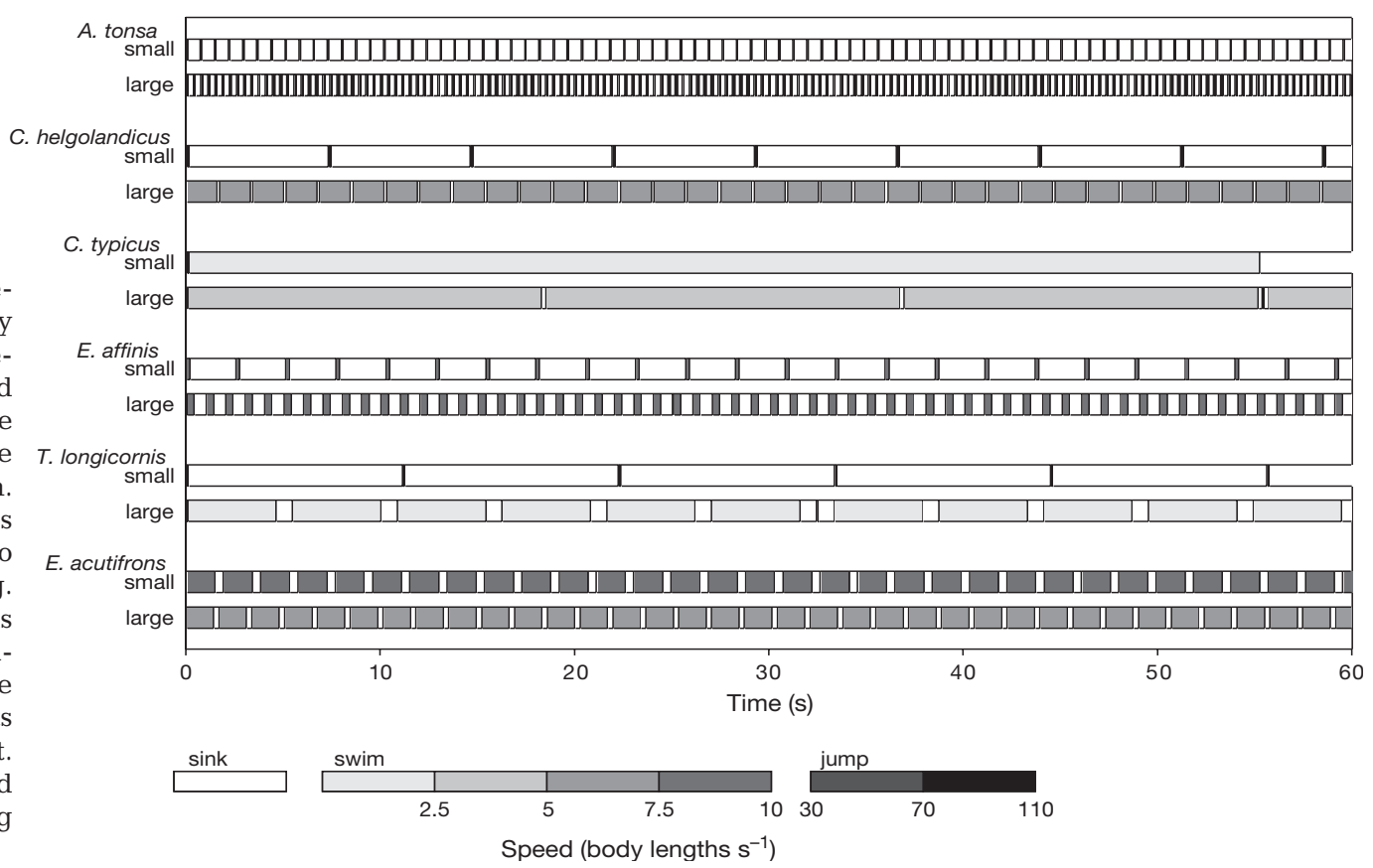


Table 2. Summary of motility for all species and stage groups. All data are arithmetic mean \pm SD. Sinking speeds for Eurytemora affinis were calculated from the regression in Fig. 3. Sizes and stage distributions are in Table 1. na is 'not applicable'

\begin{tabular}{|c|c|c|c|c|c|c|c|c|c|c|c|}
\hline \multirow{2}{*}{$\begin{array}{r}\text { Species } \\
\text { Stage }\end{array}$} & \multicolumn{2}{|c|}{ Frequency (no. $\mathrm{s}^{-1}$ ) } & \multicolumn{3}{|c|}{ Event duration $(\mathrm{s})$} & \multicolumn{3}{|c|}{ Speed $\left(\mathrm{mm} \mathrm{s}^{-1}\right)-$} & \multicolumn{3}{|c|}{-Time budget $(\%)$} \\
\hline & Swim & Jump & Sink & Swim & Jump & Sink & Swim & Jump & Sink & Swim & Jump \\
\hline \multicolumn{12}{|c|}{ Acartia tonsa } \\
\hline Early & na & $1.48 \pm 0.79$ & $0.65 \pm 0.356$ & na & $0.076 \pm 0.016$ & $0.13 \pm 0.02$ & na & $3.90 \pm 2.69$ & $86.8 \pm 7.6$ & na & $13.2 \pm 7.6$ \\
\hline Late & na & $3.05 \pm 0.94$ & $0.25 \pm 0.145$ & na & $0.12 \pm 0.04$ & $0.31 \pm 0.08$ & na & $10.38 \pm 3.25$ & $64.9 \pm 16.6$ & na & $35.1 \pm 16.6$ \\
\hline \multicolumn{12}{|c|}{ Calanus helgolandicus } \\
\hline Early & na & $0.16 \pm 0.09$ & $7.15 \pm 3.06$ & na & $0.16 \pm 0.03$ & $0.26 \pm 0.01$ & na & $24.8 \pm 11.10$ & $97.4 \pm 1.5$ & na & $2.6 \pm 1.5$ \\
\hline Late & $1.05 \pm 0.59$ & na & $0.14 \pm 0.04$ & $1.58 \pm 2.03$ & na & $0.76 \pm 0.19$ & $3.76 \pm 1.23$ & na & $15.6 \pm 10.0$ & $84.4 \pm 10.0$ & na \\
\hline \multicolumn{12}{|c|}{ Centropages typicus } \\
\hline Early & $0.023 \pm 0.029$ & $0.012 \pm 0.016$ & $5.04 \pm 7.56$ & $55.1 \pm 46.5$ & $0.14 \pm 0.11$ & $0.05 \pm 0.04$ & $0.33 \pm 0.21$ & $4.10 \pm 1.27$ & $5.1 \pm 10.1$ & $94.8 \pm 10.1$ & $0.1 \pm 0.1$ \\
\hline Late & $0.084 \pm 0.057$ & $0.028 \pm 0.033$ & $0.23 \pm 0.09$ & $18.2 \pm 13.3$ & $0.088 \pm 0.054$ & $0.14 \pm 0.07$ & $0.72 \pm 0.31$ & $10.40 \pm 1.84$ & $1.7 \pm 2.0$ & $98.0 \pm 2.1$ & $0.2 \pm 0.2$ \\
\hline \multicolumn{12}{|c|}{ Eurytemora affinis } \\
\hline Early & na & $0.43 \pm 0.13$ & $2.38 \pm 0.95$ & na & $0.19 \pm 0.04$ & 0.100 & na & $2.27 \pm 0.49^{*}$ & $91.6 \pm 4.6$ & na & $8.4 \pm 4.6$ \\
\hline Late & $1.12 \pm 0.43$ & $0.043 \pm 0.097$ & $0.62 \pm 0.36$ & $0.38 \pm 0.29$ & $0.040 \pm 0.000$ & 0.182 & $1.64 \pm 0.40$ & $11.98 \pm 5.32$ & $61.3 \pm 25.9$ & $38.7 \pm 25.9$ & $0.2 \pm 0.4$ \\
\hline \multicolumn{12}{|c|}{ Euterpina acutifrons } \\
\hline Early & $0.82 \pm 0.53$ & na & $0.43 \pm 0.58$ & $1.49 \pm 1.28$ & na & $0.09 \pm 0.05$ & $0.98 \pm 0.38$ & na & $20.1 \pm 20.5$ & $79.9 \pm 20.5$ & na \\
\hline Late & $1.18 \pm 0.84$ & na & $0.28 \pm 0.10$ & $1.41 \pm 1.74$ & na & $0.26 \pm 0.05$ & $1.08 \pm 0.31$ & na & $32.1 \pm 21.6$ & $67.9 \pm 21.6$ & na \\
\hline \multicolumn{12}{|c|}{ Temora longicornis } \\
\hline Early & na & $0.10 \pm 0.04$ & $11.0 \pm 4.26$ & na & $0.12 \pm 0.01$ & $0.09 \pm 0.03$ & na & $11.03 \pm 3.58$ & $98.8 \pm 0.1$ & na & $1.2 \pm 0.05$ \\
\hline Late & $0.20 \pm 0.04$ & $0.028 \pm 0.033$ & $0.84 \pm 0.56$ & $4.55 \pm 1.44$ & $0.087 \pm 0.016$ & $0.24 \pm 0.07$ & $0.57 \pm 0.14$ & $9.76 \pm 3.65$ & $15.8 \pm 10.2$ & $83.3 \pm 10.3$ & $0.3 \pm 0.3$ \\
\hline
\end{tabular}

nauplii were grouped into those moving with a jumpsink motion (Type A) and those swimming more or less continuously with occasional jump and sink events (Type B) (Table 3). All nauplii move in 3 dimensions regardless of their swimming mode or the continuity of their motility (Fig. 1). Sinking speeds generally increased with size and scaled with length to a power of 1.4 (Fig. 2). The exponent is less than the expected value of 2 had the nauplii been spherical and of identical density.

\section{Species- and stage-specific observations}

\section{Centropages typicus}

Both stage groups of Centropages typicus nauplii swim almost continuously at a slow pace (Table 2) using the first and second antennae and the mandibles to generate the strokes. In real time, the swimming looks smooth, but when analyzed frame by frame, short periods (up to $0.08 \mathrm{~s}$ ) of recovery appeared. Such stops were considered parts of the swimming bouts in the time budget. Occasional longer periods of sinking and fast jumps interrupt the swimming (Fig. 1). Although both stage groups used almost all their time swimming, larger nauplii shifted between moving and sinking at higher frequency than the smaller and thus, had substantially shorter event durations (Table 2). Small C. typicus exhibited the longest move events of all groups, approaching $1 \mathrm{~min}$ in mean duration (Fig. 1). Corresponding periods of sinking were also long. Velocities were twice as high for the older stage group both when swimming and jumping (Table 2). The motility results in almost perfectly symmetrical helical trails for the large nauplii, and slightly less regular ones for the small nauplii (Fig. 3). One small nauplius exhibited a hop-sink type of behavior similar to that described below for small Temora longicornis. It was not included in the time budget.

\section{Eurytemora affinis}

Eurytemora affinis nauplii change behavior quite drastically between the NI-II and older stages (Figs. 1 \& 4).

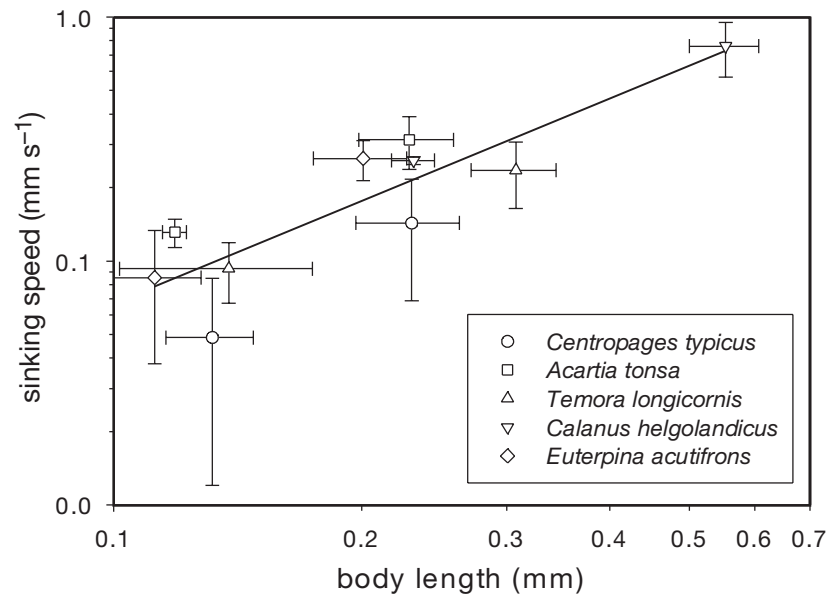

Fig. 2. Sink speed versus body length. $V_{\text {sink }}=1.68 L^{1.38}$, where $V_{\text {sink }}$ is sink speed $\left(\mathrm{mm} \mathrm{s}^{-1}\right)$ and $L$ is body length $(\mathrm{mm})$. Data from Tables $1 \& 2$ 
Table 3. General categorization of nauplii motility based on verbal, numerical, and graphical interpretations from the literature and this study. In references where there is a mismatch between verbal descriptions and numbers (e.g. 'gentle hop-like motion, $100 \%$ of the time' for Paracalanus, Paffenhöfer et al. 1996), the behavior is categorized less stringently. Björnberg (1972) verbally describes motility but without reference to time scale, or observational methods. Her descriptions are difficult to interpret and therefore excluded

\begin{tabular}{|c|c|c|c|c|c|c|}
\hline Species & Stage & $\begin{array}{l}\text { Jump-sink } \\
\text { Occasional }\end{array}$ & $\begin{array}{l}\mathrm{k} \text { (Type A) } \\
1 \text { Frequent }\end{array}$ & $\begin{array}{l}\text { Smooth sw } \\
\text { Intermittent }\end{array}$ & $\begin{array}{l}\text { im (Type B) } \\
\text { Continuous }\end{array}$ & Reference \\
\hline Acartia tonsa & I & & - & & & This study, Buskey et al. (1993) \\
\hline Acartia tonsa & IV-V & & - & & & This study \\
\hline Calanus spp. & I-II & & - & & & This study \\
\hline Calanus spp. & IV-V & & & - & & This study \\
\hline Centropages typicus & I-II & & & - & & This study \\
\hline Centropages typicus & IV-V & & & - & & This study \\
\hline Centropages velificatus & III-IV & & - & & & Paffenhöfer et al. (1996) \\
\hline Diaptomus gracilis & & & & & - & Storch (1928) \\
\hline Eurytemora affinis & I-II & & - & & & This study \\
\hline Eurytemora affinis & IV-V & & & - & & This study \\
\hline Eucalanus hyalinus & IV-VI & & & - & & Paffenhöfer et al. (1996) \\
\hline Eucalanus hyalinus & IV-VI & & & - & & Paffenhöfer \& Lewis (1989) \\
\hline Eucalanus pileatus & V-VI & & & & - & $\begin{array}{l}\text { Paffenhöfer \& Lewis (1989), } \\
\text { Paffenhöfer et al. (1996) }\end{array}$ \\
\hline Temora longicornis & I-II & & - & & & This study \\
\hline Temora longicornis & II & & & - & & van Duren \& Videler (1995) \\
\hline Temora longicornis & $\mathrm{V}-\mathrm{VI}$ & & & - & & This study, van Duren \& Videler (1995) \\
\hline Temora stylifera & IV-VI & & & & - & Paffenhöfer et al. (1996) \\
\hline Temora turbinata & late & & & & - & Paffenhöfer et al. (1996) \\
\hline Paracalanus crassiostris & I & & - & & & Buskey et al. (1993) \\
\hline Paracalanus aculeatus & IV-VI & & & - & & Paffenhöfer et al. (1996) \\
\hline Paracalanus quasimodo & V-VI & & & - & & Paffenhöfer et al. (1996) \\
\hline Euterpina acutifrons & I-II & & & - & & This study \\
\hline Euterpina acutifrons & IV-V & & & - & & This study \\
\hline Cyclops strenus & & - & & & & Storch (1928) \\
\hline Cyclops scutifer & I-IV & - & & & & Gerritsen (1978) \\
\hline Oithona similis & & - & & & & Gauld (1958) \\
\hline Oithona plumifera & I & - & & & & Buskey et al. (1993) \\
\hline Oncaea mediterranea & IV-V & - & & & & Paffenhöfer et al. (1996) \\
\hline
\end{tabular}

NI-II exhibits a jump-sink type of behavior, alternating between sinking and moving about once every $2 \mathrm{~s}$, with the vast majority of time being spent sinking (Fig. 1). Sinking events were on average 1 order of magnitude longer in duration than the moves (Table 2). The motility results in a sawtoothed translation pattern (Fig. 4).

Larger nauplii alternate between continuous fast swimming and periods of sinking at a frequency of
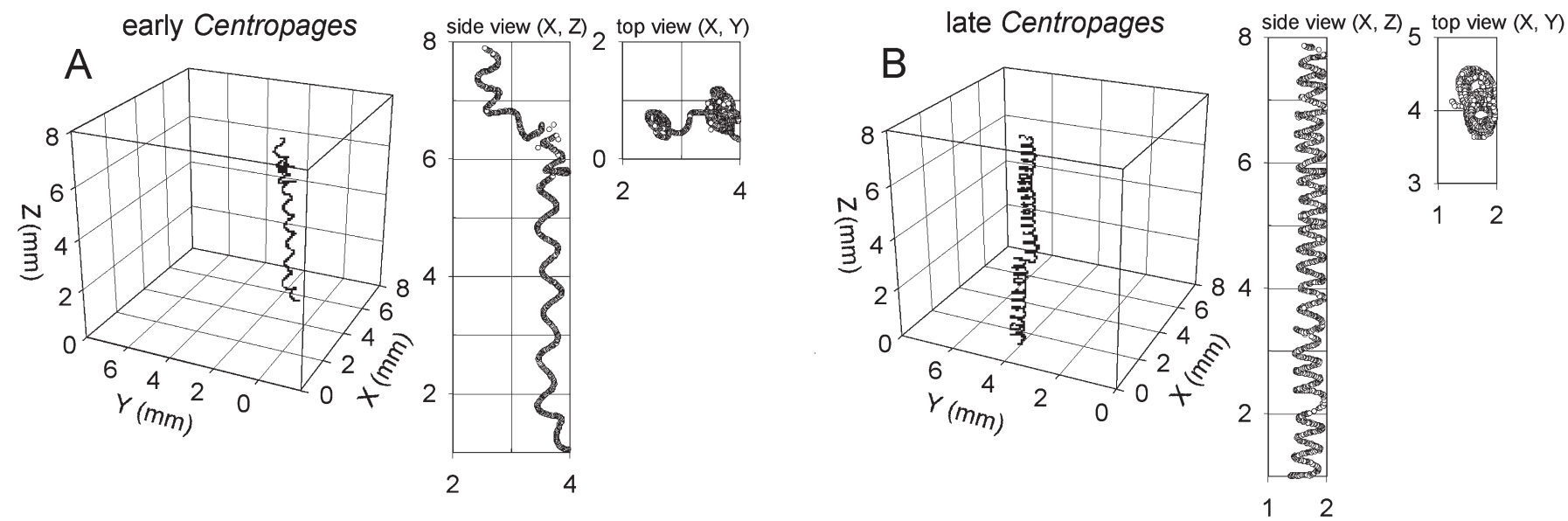

Fig. 3. Centropages typicus. Representative swim tracks of (A) early and (B) late nauplii seen from various angles. (A) Total trail length is $125.2 \mathrm{~s}$ and the time step $0.08 \mathrm{~s}$. (B) Total trail length is $90.1 \mathrm{~s}$ and the time step $0.04 \mathrm{~s}$ 

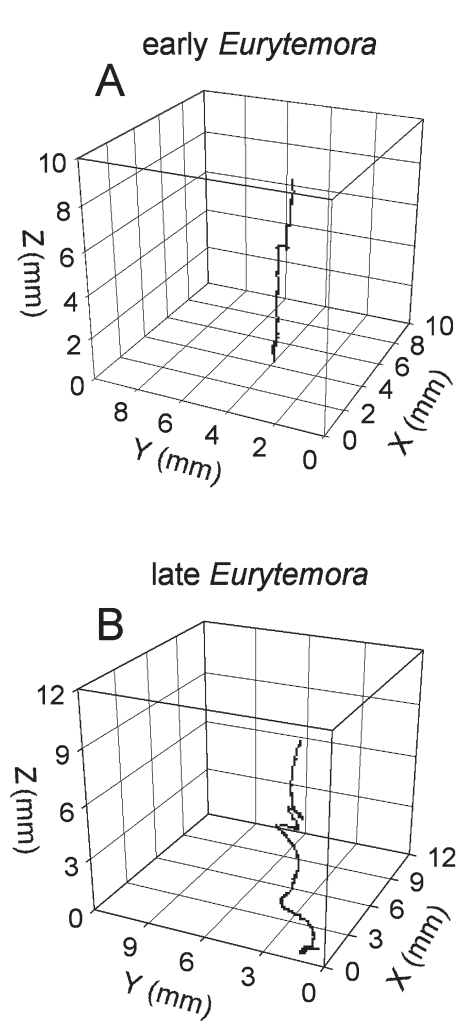

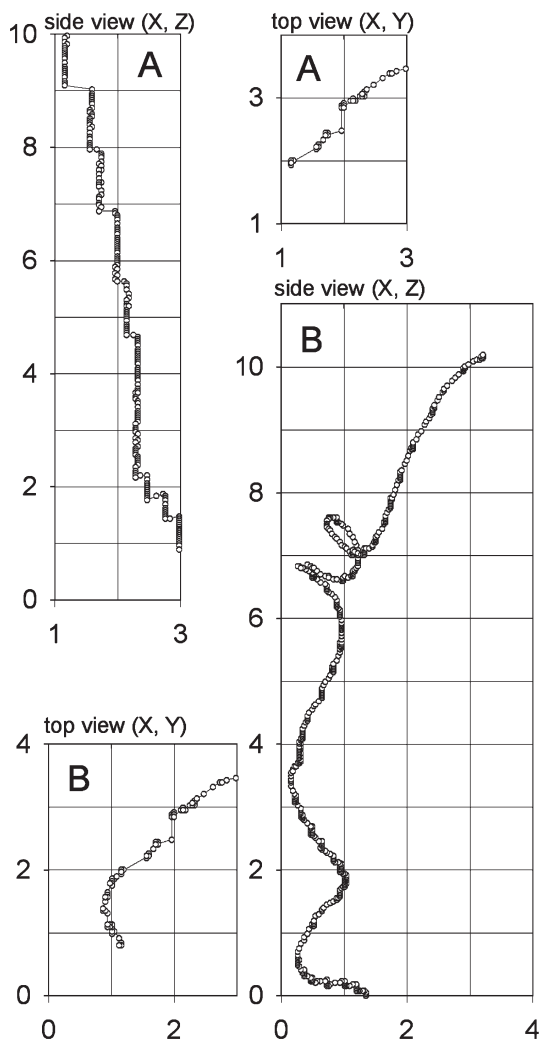

of the swimming bout in the time budget. Swimming bouts are interrupted by longer sink events. Thus, E. acutifrons exhibits a behavior that is intermediate between jumpsink and continuous fast swimming, but was here classified as swimming. Smooth, irregular loops and long stretches or waves without rapid changes in direction categorize the swim tracks of both stage groups (Fig. 5).

\section{Temora longicornis}

There is a distinct shift in behavior during the ontogeny of Temora longicornis. NI-II nauplii exhibits a clear jump-sink type of behavior, with sinking events interrupted by fast jumps several body lengths long every $10 \mathrm{~s}$ (Table 2). The sawtooth tracks of $T$. longicornis NI-II clearly illustrate the jump-sink behavior (Fig. 6). Larger nauplii swam with an almost continuous, slow, smooth glide (Table 2). Brief stops of up to $0.04 \mathrm{~s}$ were included in the swimming bouts in the time budget. The swim was interrupted by periods of sinking and by fast jumps, but the majority

Fig. 4. Eurytemora affinis. Representative swim tracks of (A) early and (B) late nauplii. (A) Total trail length is $19.28 \mathrm{~s}$ and the time step $0.08 \mathrm{~s}$.

(B) Total trail length is $40.36 \mathrm{~s}$ and the time step $0.04 \mathrm{~s}$

about twice that of the smaller nauplii, spending $~ 60 \%$ of the time motionless (Table 2). Distinct jumps are present only occasionally. Swimming events are on average about half the duration of the sink events. Swim paths are irregularly shaped with occasional loops (Fig. 4). Sink speeds could not be adequately determined because of convection in the aquaria, but were estimated using the regression in Fig. 2 (Table 2).

\section{Euterpina acutifrons}

Motility of the 2 stage groups of Euterpina acutifrons is similar in most parameters and in overall appearance of the trails (Fig. 5, Table 2). Swimming bouts of both stage groups consist of cycles of fast movements up to $0.12 \mathrm{~s}$ in duration punctuated by recovery periods lasting up to $0.08 \mathrm{~s}$. These brief stops were considered part

Fig. 5. Euterpina acutifrons. Representative swim tracks of (A) early and (B) late nauplii. (A) Total trail length is $14.88 \mathrm{~s}$ and the time step $0.04 \mathrm{~s}$. (B) Total trail length is $17.64 \mathrm{~s}$ and the time step $0.04 \mathrm{~s}$
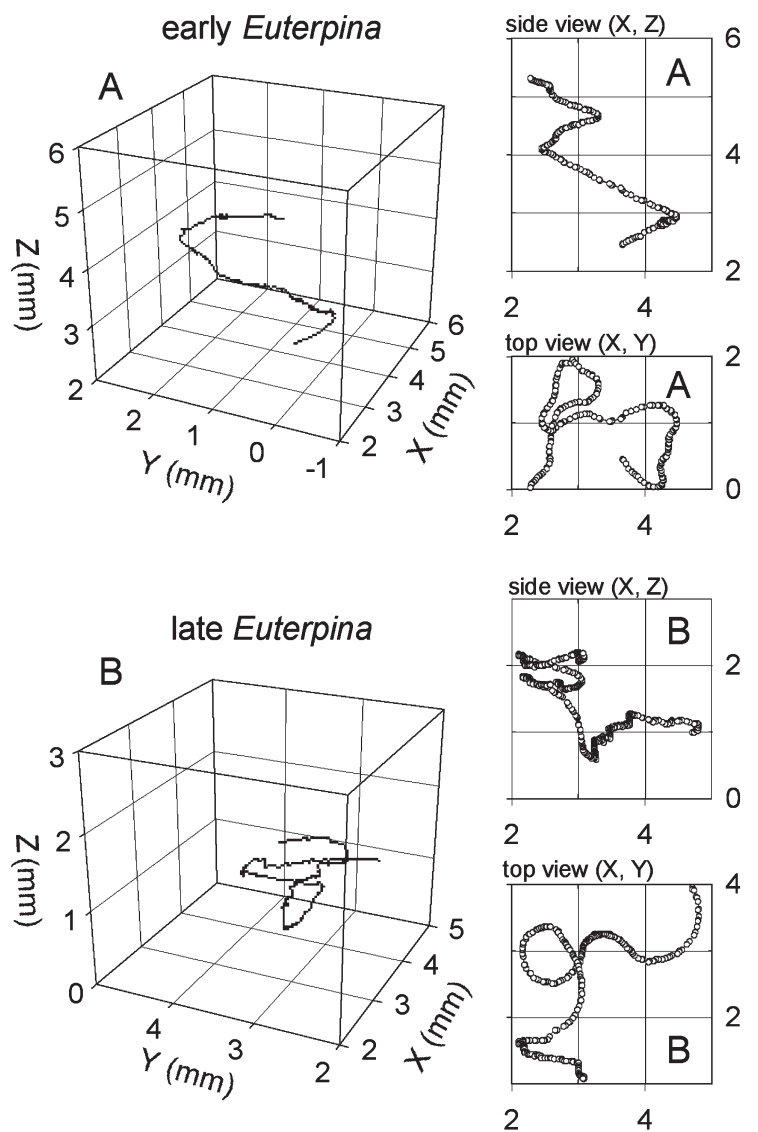


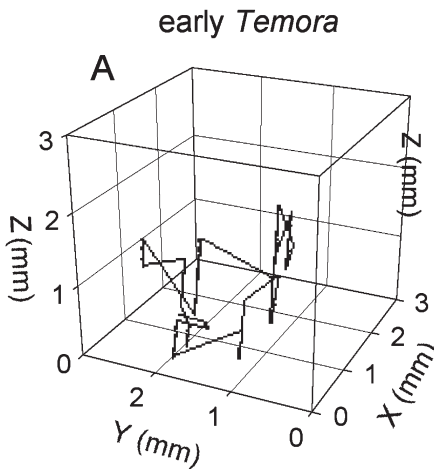

late Temora
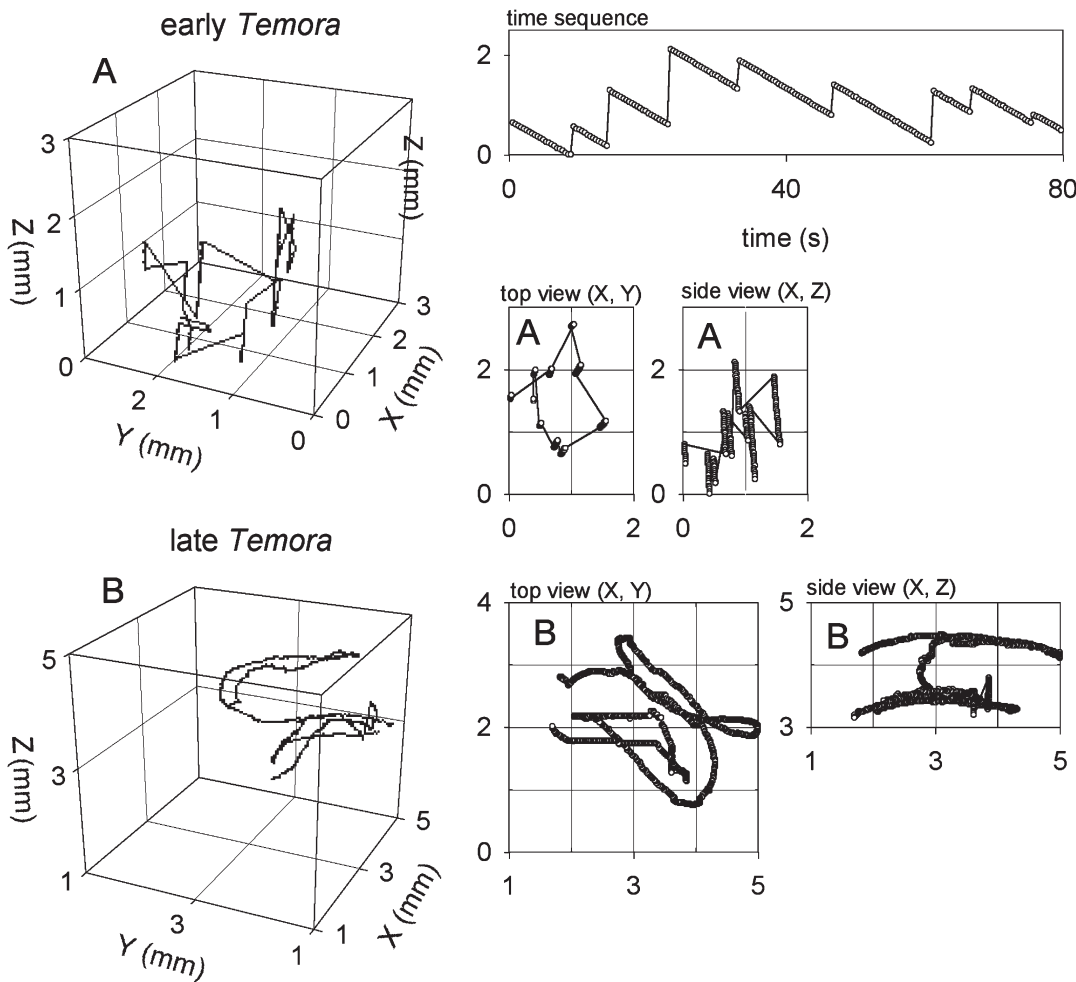

of the time was spent swimming (Fig. 1, Table 2). The resulting tracks of the NV-VI group are smooth and distinctly different from the tracks of the NI-II (Fig. 6).

\section{Calanus helgolandicus}

Calanus helgolandicus changes behavior drastically during ontogeny. The NI-II moves in a characteristic jump-sink manner, where long fast jumps of very short durations interrupt long periods of sinking (Figs. 1 \& 7 , Table 2). Larger nauplii swam in a smoother, more continuous fashion (Figs. 1 \& 7, Table 2). Brief stops of up to $0.08 \mathrm{~s}$ interrupt the swimming, but were included in the swimming bouts for time budgets. Longer periods of sinking and occasional jumps intermit the swimming bouts, but the vast majority of time is spent swimming (Table 2). Motility of the larger $C$. helgolandicus nauplii results in swim trails of 2 types. The first consists of

Fig. 7. Calanus helgolandicus. Representative swim tracks of (A) early and (B) late nauplii. (A) Total trail length is $95.2 \mathrm{~s}$ and the time step $0.08 \mathrm{~s}$. (B) Total trail lengths are $47.28 \mathrm{~s}$ for the wavy trail and 28.6 for the helical one, and the time step is $0.04 \mathrm{~s}$ for both

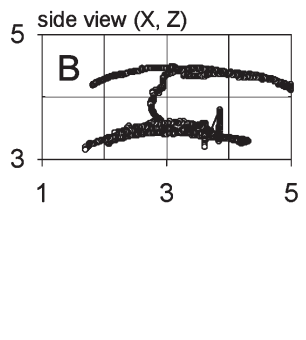

Fig. 6. Temora longicornis. Representative swim tracks of (A) early and (B) late nauplii. (A) Total trail length is $79.84 \mathrm{~s}$ and the time step $0.08 \mathrm{~s}$.

(B) Total trail length is $45.52 \mathrm{~s}$ and the time step $0.04 \mathrm{~s}$

long stretches without rapid changes in direction and the second is a symmetric helix (Fig. 7).

\section{Acartia tonsa}

Although both the small and the larger stages of Acartia tonsa move in a jumpsink fashion, spending most of the time motionless, frequencies, durations and velocities differ between the stage groups as do the resulting swim tracks (Figs. 1 \& 8 Table 2). The fraction of time spent moving is twice as high for the older nauplii, as is the frequency at which the nauplii alternate between sinking and moving (Table 2). While the sinking events are ca. 10 -fold longer than the move events for the NI-II, they are only 2-fold longer for the
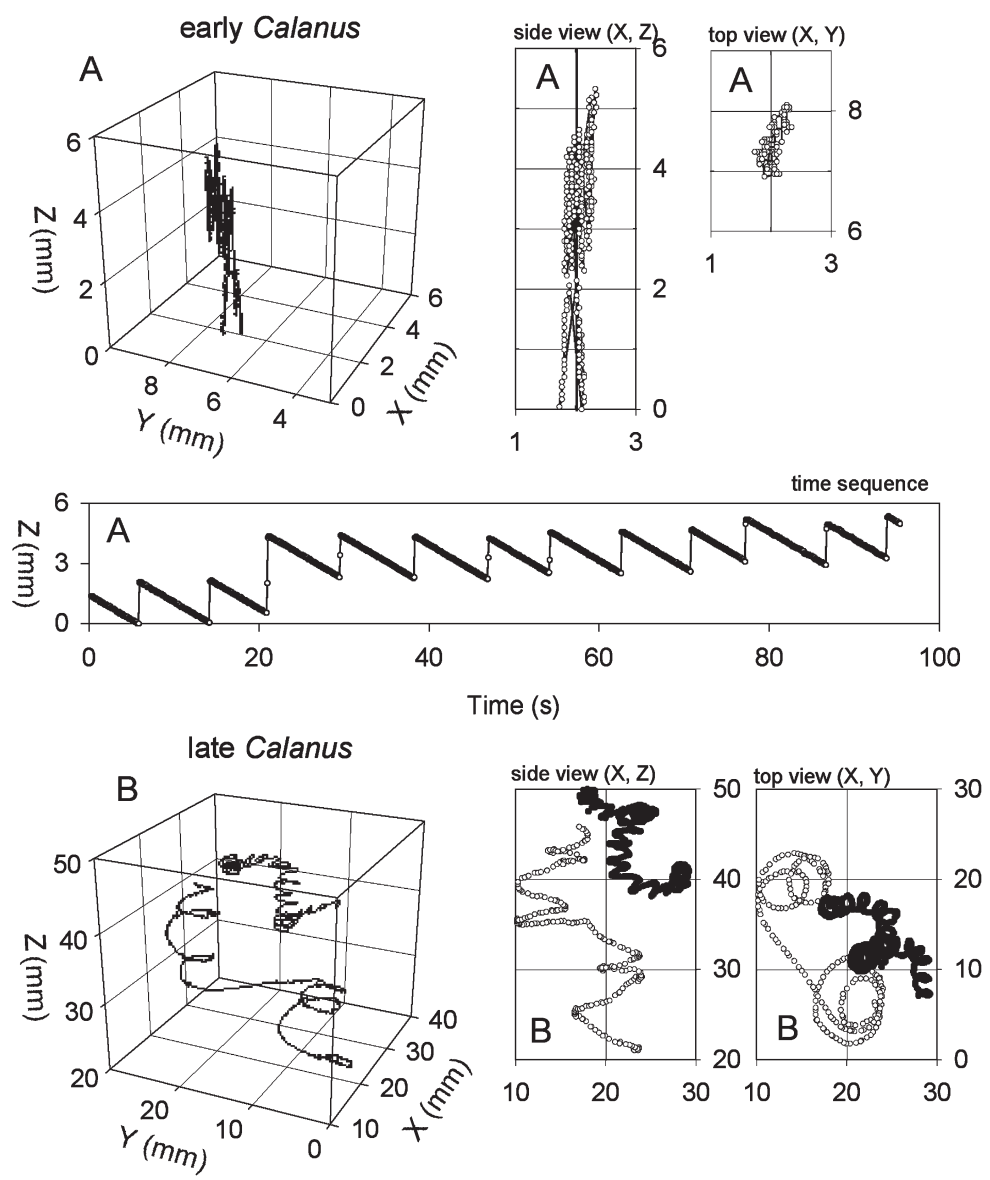


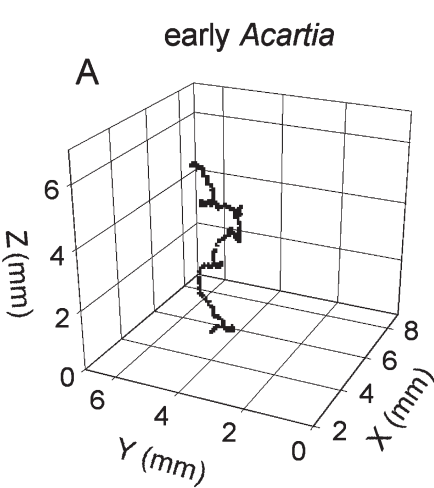

late Acartia
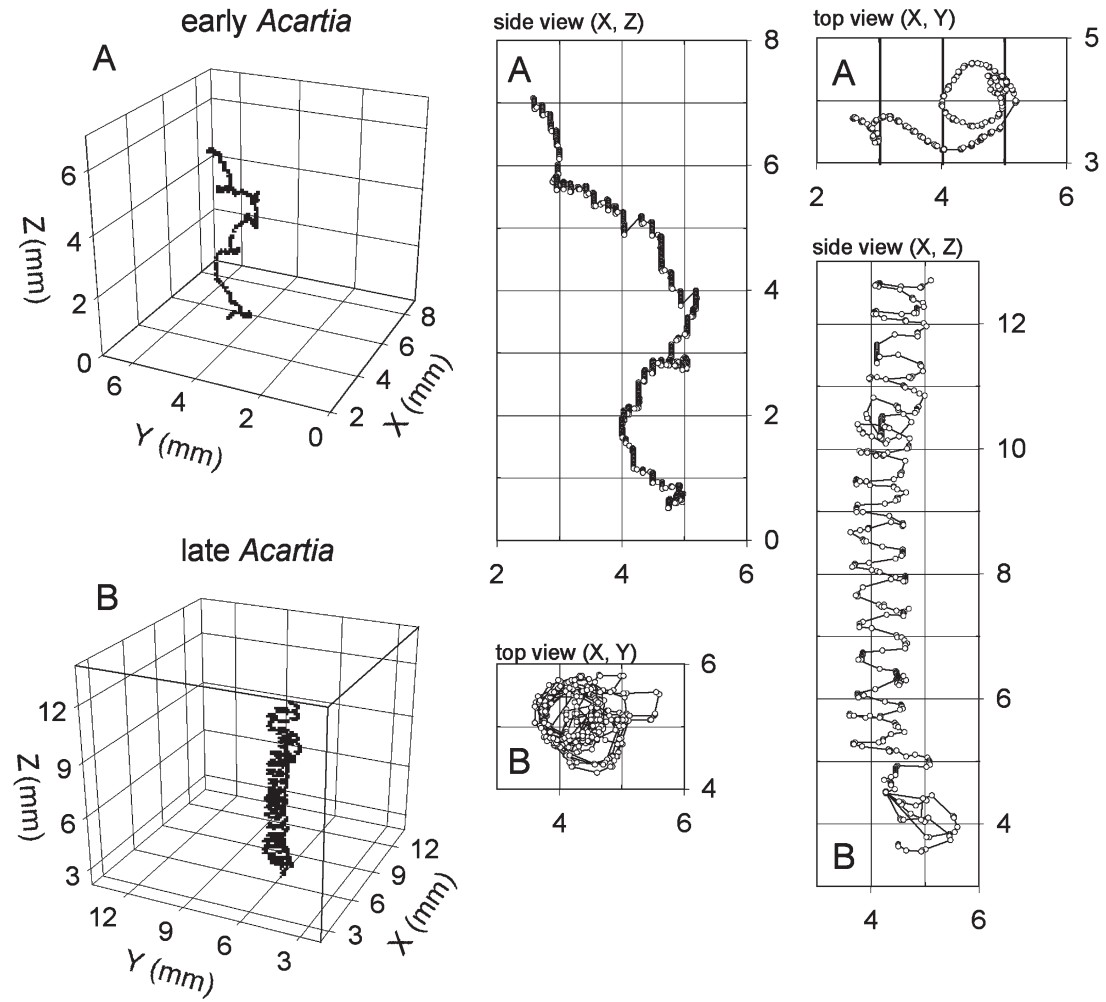

Fig. 8. Acartia tonsa. Representative swim tracks of (A) early and (B) late nauplii. (A) Total trail length is $66.4 \mathrm{~s}$ and the time step $0.04 \mathrm{~s}$. (B) Total trail length is $17.3 \mathrm{~s}$ and the time step $0.04 \mathrm{~s}$

NV-VI (Table 2). Jump speed doubles during naupliar ontogeny (Table 2). For the NI-II, the fast bursts usually result in a sawtooth random trail with occasional loops (Fig. 8). For later stages, the hop-sink behavior resulted in 1 of 3 patterns. The first is similar to that of the NI-II and the second is an almost straight path, resulting from the nauplius making repeated but unidirectional jumps (track not shown). The third and most common trail is an almost perfectly symmetrical helix (Fig. 8) with a loop frequency of $1.3 \mathrm{~s}^{-1}$. The distance between subsequent loops is approximately $1 / 4$ of the loop diameter.

\section{DISCUSSION}

\section{Motility}

Several qualitative descriptions of naupliar motility exist (e.g. Björnberg 1972, Storch 1928, Gauld 1958); however, it is difficult to characterize motility based solely on verbal descriptions (Table 4, references therein) or 2D depictions of swim tracks (Bresciani 1960, Björnberg 1972, Gerritsen 1978, Buskey et al. 1993, Paffenhöfer et al. 1996). Similarly, our impression of motility depends on the temporal and spatial resolution of observations and motion analyses. When comparing our observations with the quantitative data available (Table 4), many movement speeds (e.g. Gerritsen 1978, Buskey et al. 1993) are lower than those observed here (Table 2). This offset results from sinking events being included in most reported estimates of movement velocities. Also, observations made in 2D underestimate actual distances and velocities.

When the nauplii are observed in 3D and temporal resolution is increased, the behavior can be separated into different types of events, and a more nuanced depiction of the activity pattern emerges. Behaviors and visual impressions of the motility are as stage- and species-specific (Fig. 1) as the morphologies. Brief stops of less than $1 \mathrm{~s}$ to several seconds occurred for all species and stages observed here (Fig. 1). Even within individual swim events brief stops of $<0.08 \mathrm{~s}$ are common. With the spatio-temporal resolution used here to characterize motility patterns, even nauplii with apparently similar behaviors turn out different (Fig. 1, Table 3). None of the species or stages observed here spends all its time moving, contradicting the notion of Paffenhöfer et al. (1996) that most calanoid nauplii move all of the time. However, they discounted stops 'of a fraction of a second', which of course leads to inflated estimates of activities. In fact, a jump-sink type of behavior similar to that of many cyclopoid and poecilostomatoid nauplii (Gauld 1958, Björnberg 1972, Buskey et al. 1993, Paffenhöfer et al. 1996) is common in NI-II of many calanoid species (Fig. 1), as was also observed by Buskey et al. (1993) for NI of Paracalanus crassiostris.

While some copepod species exhibit a similar behavior throughout ontogeny (e.g. Oithona spp.) or from late naupliar stages to adults (e.g. Temora stylifera; Paffenhöfer 1998), other species change drastically (e.g. Cyclops scutifer, Gerritsen 1978). One may expect significant behavioral changes to occur simultaneously with dramatic morphological changes, for example between NVI and CI, as is the case for Centropages velificatus (Paffenhöfer et al. 1996) or simultaneously with the shift between non-feeding and feeding stages. Clearly significant behavioral changes occur during naupliar development for many species (Fig. 1).

Björnberg (1986a,b), Huys \& Boxshall (1991) and Paffenhöfer (1998) argued for the use of motility pat- 
Table 4. Literature summary of naupliar motility parameters. Reported movement velocities exclude or include periods of sinking. Unless otherwise noted, data stem from 2D measurements. Superscripts indicate the following: ${ }^{*}$ calculated from data in reference; ${ }^{1}$ measured or calculated in $3 \mathrm{D}_{i}{ }^{2}$ excluding jump; ${ }^{3}$ from figure in specified reference. na is 'not applicable'

\begin{tabular}{|c|c|c|c|c|c|c|}
\hline \multirow[t]{2}{*}{ Species } & \multirow[t]{2}{*}{ Stage } & \multirow[t]{2}{*}{$\begin{array}{l}\text { Length } \\
(\mu \mathrm{m})\end{array}$} & \multicolumn{2}{|c|}{$\begin{array}{l}\text { Movement speed } \\
\left(\mathrm{mm} \mathrm{s}^{-1}\right)\end{array}$} & \multirow[t]{2}{*}{$\begin{array}{c}\text { Movement time } \\
(\%)\end{array}$} & \multirow[t]{2}{*}{ Reference } \\
\hline & & & Excl. sink & Incl. sink & & \\
\hline Acartia clausii & $\begin{array}{l}\text { III } \\
\text { IV } \\
\text { V } \\
\text { VI }\end{array}$ & $\begin{array}{l}- \\
- \\
- \\
-\end{array}$ & $\begin{array}{l}- \\
- \\
- \\
-\end{array}$ & $\begin{array}{l}0.50^{1} \\
0.59^{1} \\
0.70^{1} \\
0.45^{1}\end{array}$ & $\begin{array}{l}- \\
- \\
- \\
-\end{array}$ & $\begin{array}{l}\text { Landry \& Fagerness (1988) } \\
\text { Landry \& Fagerness (1988) } \\
\text { Landry \& Fagerness (1988) } \\
\text { Landry \& Fagerness (1988) }\end{array}$ \\
\hline Acartia tonsa & $\begin{array}{c}\mathrm{I} \\
\mathrm{I} \\
\mathrm{IV}-\mathrm{VI}\end{array}$ & $\begin{array}{c}- \\
84 \\
198 \pm 9.8\end{array}$ & $\begin{array}{c}\sim 1 \\
- \\
5.8 \pm 1.78\end{array}$ & $\begin{array}{l}0.39 \\
0.04 \\
0.71^{*}\end{array}$ & $\begin{array}{c}\sim 55 \\
- \\
12.3 \pm 4.18\end{array}$ & $\begin{array}{l}\text { Buskey (1994) } \\
\text { Buskey et al. (1993) } \\
\text { Titelman (2001) }\end{array}$ \\
\hline Calanus pacificus & $\begin{array}{l}\text { III } \\
\text { V } \\
\text { VI }\end{array}$ & $\begin{array}{l}- \\
- \\
-\end{array}$ & $\begin{array}{l}- \\
- \\
-\end{array}$ & $\begin{array}{l}1.24^{1} \\
1.23^{1} \\
1.08^{1}\end{array}$ & $\begin{array}{l}- \\
- \\
-\end{array}$ & $\begin{array}{l}\text { Landry \& Fagerness (1988) } \\
\text { Landry \& Fagerness (1988) } \\
\text { Landry \& Fagerness (1988) }\end{array}$ \\
\hline Centropages velificatus & III-V & $220-360$ & $2.73 \pm 0.12$ & 0.23 & $8.5 \pm 1.5$ & Paffenhöfer et al. (1996) \\
\hline Eucalanus hyalinus & IV-VI & $771-1150$ & $0.61 \pm 0.07$ & na & 100 & Paffenhöfer et al. (1996) \\
\hline Eucalanus pileatus & IV-VI & $370-600$ & $0.78 \pm 0.09$ & na & 100 & Paffenhöfer et al. (1996) \\
\hline Temora longicornis & $\begin{array}{c}\text { II } \\
\text { VI } \\
\text { IV-VI }\end{array}$ & $\begin{array}{c}- \\
- \\
298 \pm 38\end{array}$ & $\begin{array}{c}\sim 1.5^{3} \\
\sim 1.5-2.0^{3} \\
0.82 \pm 0.18^{2}\end{array}$ & $\begin{array}{l}0.86^{*} \\
0.86^{*} \\
0.49^{*}\end{array}$ & $\begin{array}{c}57.3 \pm 3.8 \\
57.5 \pm 2.4 \\
59.6 \pm 29.6\end{array}$ & $\begin{array}{l}\text { van Duren \& Videler (1995) } \\
\text { van Duren \& Videler (1995) } \\
\text { Titelman (2001) }\end{array}$ \\
\hline Temora stylifera & IV-VI & $200-280$ & $0.39 \pm 0.01$ & na & 100 & Paffenhöfer et al. (1996) \\
\hline Temora turbinate & $?$ & - & 0.50 & - & - & Paffenhöfer et al. (1996) \\
\hline Paracalanus acculeatus & IV-VI & $180-260$ & $0.67 \pm 0.09$ & na & 100 & Paffenhöfer et al. (1996) \\
\hline Paracalanus crassiostris & I & 74 & $\sim 2.5-5^{3}$ & 0.16 & - & Buskey et al. (1993) \\
\hline Paracalanus quasimodo & $\mathrm{V}-\mathrm{VI}$ & $180-220$ & $1.34 \pm 0.16$ & na & 100 & Paffenhöfer et al. (1996) \\
\hline Pseudocalanus sp. & $\begin{array}{c}\text { III } \\
\text { IV } \\
\text { V } \\
\text { VI }\end{array}$ & $\begin{array}{l}- \\
- \\
- \\
-\end{array}$ & $\begin{array}{l}- \\
- \\
- \\
-\end{array}$ & $\begin{array}{l}0.76^{1} \\
0.93^{1} \\
1.22^{1} \\
0.41^{1}\end{array}$ & $\begin{array}{l}- \\
- \\
- \\
-\end{array}$ & $\begin{array}{l}\text { Landry \& Fagerness (1988) } \\
\text { Landry \& Fagerness (1988) } \\
\text { Landry \& Fagerness (1988) } \\
\text { Landry \& Fagerness (1988) }\end{array}$ \\
\hline Pseudodaptimus coronatus & S II & 147 & - & 0.31 & - & Buskey et al. (1993) \\
\hline Coryceaus sp. & I & 103 & - & 0.06 & - & Buskey et al. (1993) \\
\hline Cyclops scutifer & $?$ & - & - & $0.2-0.3$ & - & Gerritsen (1978) \\
\hline Oithona simplex & I & 91 & - & 0.15 & - & Buskey et al. (1993) \\
\hline Oithona plumifera & I & 83 & $\sim 5-6^{3}$ & 0.06 & - & Buskey et al. (1993) \\
\hline Oncaea mediterranea & IV-V & $140-170$ & $5.24 \pm 0.44$ & 0.10 & $1.9 \pm 0.34$ & Paffenhöfer et al. (1996) \\
\hline
\end{tabular}

terns during ontogeny as a complement to morphology in phylogenetic studies. When considering the data resulting from this study in conjunction with that available in the literature for nauplii (Tables 3 \& 4) and copepodids (reviewed in Mauchline 1998), there is, however, no obvious way of categorizing motility in a fashion that coincides with taxonomy as suggested by Paffenhöfer et al. (1996). However, the motility pattern is almost as good a diagnostic character for species identification as are morphological characters.

\section{Energetic costs of motility}

The energetic cost of swimming in copepods moving at low Reynolds numbers is normally considered to be very low (e.g. Kiørboe et al. 1985). However, the power requirement increases with the move velocity squared and may thus become significant for nauplii that jump with high velocities and at high frequencies, e.g. Acartia tonsa. The average power required for propulsion, $P\left(\mathrm{~J} \mathrm{~s}^{-1}\right)$ is (e.g. Berg 1993):

$$
P=\tau 6 \pi \eta a v^{2}
$$

where $\eta$ is the dynamic viscosity of the ambient fluid $\left(\sim 10^{-3} \mathrm{~kg} \mathrm{~m}^{-1} \mathrm{~s}^{-1}\right), a$ is the radius of the nauplius $(\mathrm{m}), v$ its movement velocity $\left(\mathrm{m} \mathrm{s}^{-1}\right)$ and $\tau$ the fraction of time moving. Using data from Tables 1 \& 2 on sizes and movement velocities, the estimated power required for swimming in small and large Centropages typicus, for example, is $1.3 \times 10^{-13}$ and $1.6 \times 10^{-12} \mathrm{~J} \mathrm{~s}^{-1}$, respectively. These values correspond to only tiny fractions of overall metabolism. The latter can be estimated from 
published relations of oxygen uptake as a function of body mass in calanoid copepods $\left(\mathrm{R}\left[\mu \mathrm{O} \mathrm{O} \mathrm{h}^{-1}\right]=\right.$ $1.75 \mathrm{~W}[\mathrm{mg} \text { dry wt] }]^{0.79}$, Mauchline 1998) to be about $4 \times 10^{-9}$ and $2.5 \times 10^{-8} \mathrm{~J} \mathrm{~s}^{-1}$ for small and large $C$.

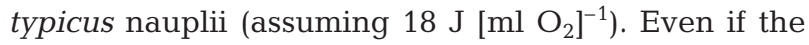
efficiency of propulsion is only say $1 \%$, metabolic requirements for swimming constitute $<1 \%$ of the metabolism. Similarly low power requirements are estimated for all other groups with the exception of Acartia tonsa. In A. tonsa, the estimated power requirement to sustain the high jumping frequency constitutes 5 and $30 \%$ of the overall metabolism for small and large nauplii (again assuming $1 \%$ efficiency). Although this estimate is crude, it does suggest that jumping may be energetically expensive. One would thus expect that there is some advantage of jumping with a high frequency.

\section{Implications of motility for food encounter}

Because motility in copepods is tightly connected to feeding, it is worthwhile to examine the behavior of nauplii in this context. Essentially, we have observed 2 different motility patterns among nauplii, i.e. those that move in a jump-sink fashion (most young stages of calanoids, and all stages of cyclopoid and poecilostomatoid nauplii), and those that cruise through the water more or less continuously (most older stages of calanoid nauplii) (Table 3). Among the jumping nauplii, some jump only rarely (e.g. 1 to $2 \mathrm{~min}^{-1}$, most poiceilostomatids and cyclopoids), while others jump frequently (e.g. $3 \mathrm{~s}^{-1}$, late Acartia tonsa). Because nauplii are most likely unable to collect food particles during rapid jumps, one would at first expect that a cruising strategy would allow the nauplii to scan a much larger volume of water for food particles than a jump-sink strategy and hence, yield higher clearance rates. The few clearance rates reported for nauplii in fact suggest a difference in clearance rates between the 2 motility types, although it is not dramatic (Fig. 9A). Maximum growth rates of nauplii of the 2 categories appear to be similar (Heinle \& Flemer 1975, Klein Breteler et al. 1982, Paffenhöfer 1993, Sabatini \& Kiørboe 1994, Kiørboe \& Sabatini 1995). Hence, both motility types imply food clearance rates of similar magnitude.

Clearance rates may be modeled from motility behavior by deriving encounter rate kernels (= clearance rate if capture efficiency is $100 \%$ ). For cruising nauplii, the encounter rate kernel is:

$$
\beta_{\text {cruise }}=\tau \pi R^{2} \Delta V
$$

where $R$ is the radius of the (assumed) spherical capture volume, $\tau$ is the fraction of time spent swimming, and $\Delta v$ is the velocity difference between the nauplius and the food. If we take $1 / 2$ the length of the nauplii as a first estimate of $R$ and consider only non-motile food, then we can estimate potential clearance rates for cruising nauplii using sizes, swimming speeds and time budgets as reported in Tables 1 \& 2 (Fig. 10B).
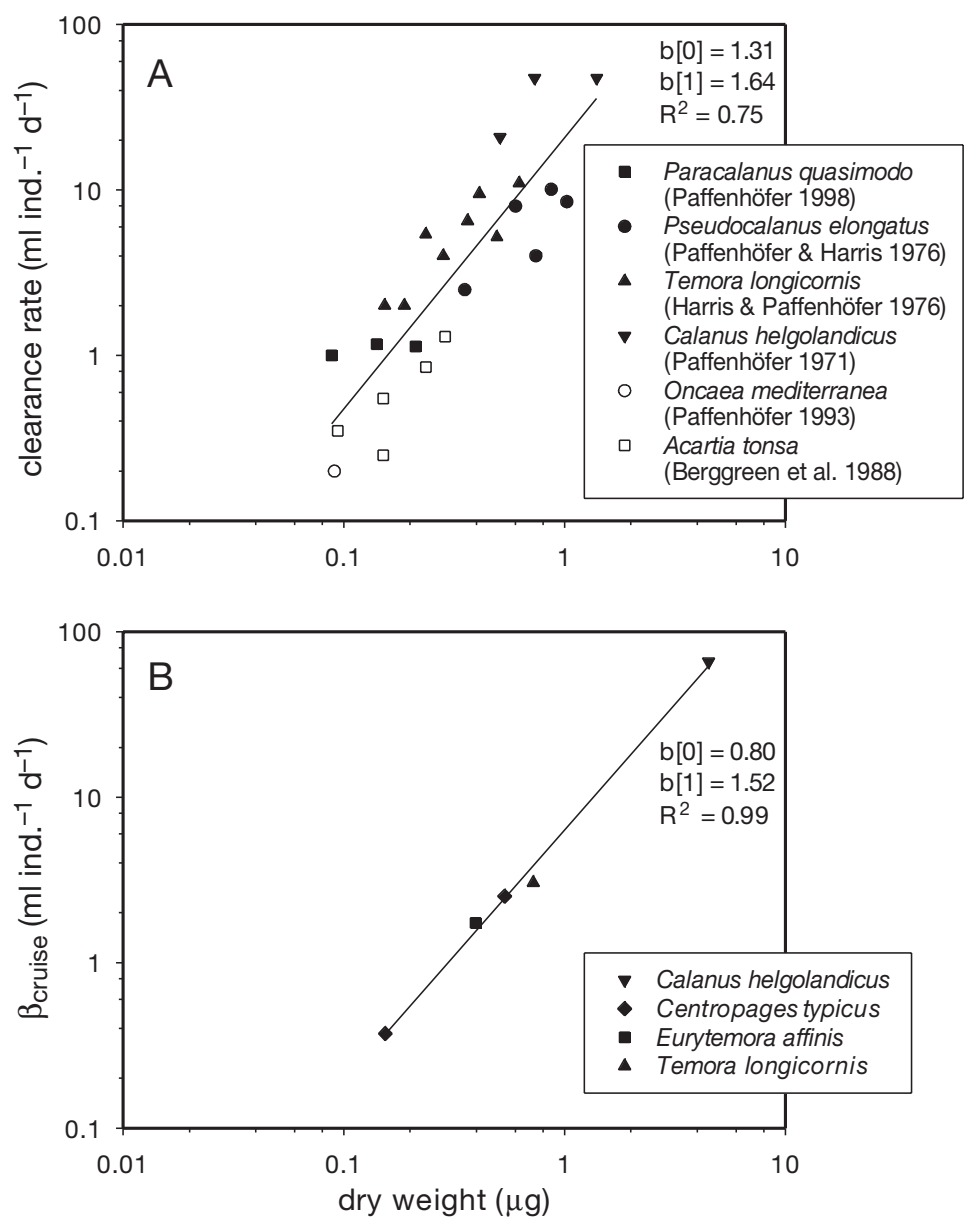

Fig. 9. (A) Published clearance rates for nauplii feeding on phytoplankton. White symbols indicate jump-sink motility and black symbols indicate a more-or-less continuous swim. Data are from visual inspection of graphs or tables in the specified references. When several food concentrations were offered in the experiments, we used only data from the lowest prey concentration. Similarly, only stagespecific maximum clearance rates are used from those studies where a range of prey were offered. We assumed $15 \%$ ash and $45 \%$ carbon content in conversions to dry weight (Mauchline 1998). (B) Estimated $\beta_{\text {cruise }}$ from Eq. (2) for nauplii with a more-or-less continuous swim. We applied sizes from Table 1, and behavioral data from Table 2. Lengths were converted to dry weights using regressions in Klein Breteler et al. (1982, Temora longicornis; Calanus helgolandicus using equation for Pseudocalanus), Hay et al. (1991, Centropages typicus; Eurytemora affinis using equation for C. typicus) 
Predicted clearance rates are similar to those actually measured (Fig. 9). Feeding on motile prey will not change the predicted clearance rates much since naupliar swimming velocities are typically significantly higher than those of their prey. The swimming behavior of cruising nauplii can easily account for observed clearance rates.

For nauplii with a jump-sink behavior, it is unlikely that food search occurs during the active jump. Rather, the jump relocates the nauplius to a new spot in which it can search for food. Assuming that all prey within the dining sphere are in fact encountered, the encounter rate kernel for such a pause-travel strategy is (Kiørboe 1997):

$$
\beta_{\text {pause-travel }}=\frac{4 \pi R^{3} f_{\text {jump }}}{3}
$$

where $f_{\text {jump }}$ is the jump frequency $\left(\mathrm{s}^{-1}\right)$. Estimated potential clearance rate increases linearly with jump frequency and becomes similar to observed clearance rates for frequent jumpers, such as late Acartia tonsa (Fig. 10). However, with increasing jump frequencies, the time spent at each spot declines and Eq. (3) therefore, presumably overestimates clearance rates for the frequent jumpers. For species that jump only occasionally, potential clearance rates according to Eq. (3) are much smaller than those reported. For example, Oncaea NV, which jumps only rarely (1 to $2 \mathrm{~min}^{-1}$ ), has a predicted potential clearance rate of $\sim 0.01 \mathrm{ml} \mathrm{d}^{-1}$ $(R \sim 100 \mu \mathrm{m})$, more than 1 order of magnitude less that measured, $0.2 \mathrm{ml} \mathrm{d}^{-1}$ (Paffenhöfer 1993). Thus, Eq. (3) appears inconsistent with observed clearance rates in jumping nauplii, particularly in the case of rare jumpers.

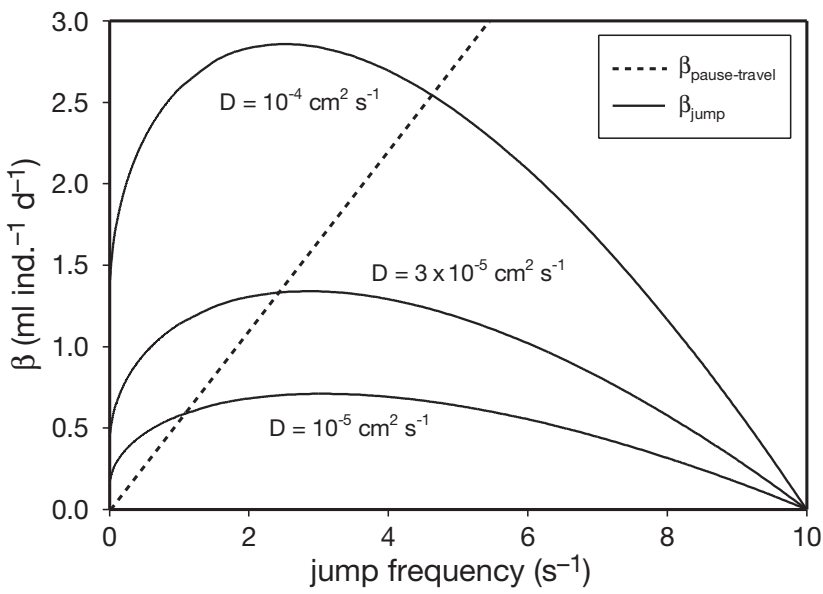

Fig. 10. Encounter-rate kernels for jump-sink nauplii. $\beta_{\text {jump }}$ is the predicted volume encounter rate due to diffusion of prey calculated from Eq. (6d) assuming $\alpha=0.1 \mathrm{~s}$ and $R=0.0115 \mathrm{~cm}$ for values of $D$ of $10^{-5}, 3 \times 10^{-4}$ and $10^{-4} \mathrm{~cm}^{2} \mathrm{~s}^{-1}$. $\beta_{\text {pause-travel }}$ is calculated from Eq. (3) for $R=0.0115 \mathrm{~cm}$
Nauplii may also encounter food as they sink. It is difficult to accurately estimate the clearance rate due to this mechanism. The nauplius pushes water and food away as it sinks. If we ignore this hydrodynamic effect, then the encounter rate kernel for sinking is similar to that for cruising:

$$
\beta_{\text {sink }}=(1-\tau) \pi R^{2} v_{\text {sink }}
$$

However, if we instead model the sinking nauplius as a solid sphere that directly intercepts prey particles, then (Kiørboe \& Titelman 1998):

$$
\beta_{\text {intercept }}=(1-\tau) 1.5 \pi a^{2} v_{\text {sink }}
$$

where $a$ is the radius of the prey. The truth probably lies somewhere between that predicted by Eqs. (4a) \& (4b). Prey encounter rates predicted by Eq. (4b) are orders of magnitude lower than those actually observed.

Both Eqs. (3) and (4) significantly underestimate the clearance rate of jumping nauplii if the prey is motile. This is because such nauplii only move slowly during prey encounter and prey motility therefore becomes relatively more important than for cruising nauplii. We thus need to consider prey motility for pause-travel nauplii.

Most protists swim in a more or less random manner and their motility may be described as a random walk and quantified by a diffusion coefficient $(D)$. For protists that swim in a run-tumble fashion, the diffusivity can be estimated as (Berg 1993):

$$
D=\frac{t v_{\text {prey }}^{2}}{6}
$$

where $t$ is the average duration of runs and $v_{\text {prey }}$ the swimming velocity. At steady state, the diffusion of prey towards the nauplius is quantified by the encounter rate kernel:

$$
\beta_{\text {st.state }}=4(1-\tau) \pi R D
$$

where $(1-\tau)$ is the fraction of time spent pausing. However, because the nauplii relocate more or less frequently, steady state cannot generally be assumed and therefore, the encounter rate kernel becomes timedependent (Osborn 1996):

$$
\beta_{t}=4 \pi D\left(R+\left[\frac{R^{2}}{(\pi D t)^{0.5}}\right]\right)
$$

The average encounter rate kernel during a time period $T$, equal to the average time interval between jumps is then:

$$
\beta_{\text {average }}=\frac{\int_{0}^{T} \beta_{t} \mathrm{~d} t}{T}
$$

and the encounter rate kernel for jumpers then becomes: 


$$
\begin{aligned}
\beta_{\text {jump }} & =(1-\tau) \frac{\int_{0}^{T} \beta_{t} \mathrm{~d} t}{T}=4(1-\tau) \pi D\left(R+\frac{2 R^{2}}{(\pi D T)^{0.5}}\right) \\
& \approx 4(1-\alpha f) \pi D\left(R+\frac{2 R^{2} f^{0.5}}{(\pi D)^{0.5}}\right)
\end{aligned}
$$

where we utilize that $\tau=\alpha f$, where $\alpha$ is average duration of a jump event and $T=(1-\alpha f) / f \approx f^{-1}$ for small $\alpha$.

Eq. 6 has 2 implications. First, prey motility may account for the clearance rates observed in 'rare' jumpers, suggesting that they depend on motile food. Assuming a representative value of $D$ for the prey of $3 \times 10^{-5} \mathrm{~cm}^{2} \mathrm{~s}^{-1}$, as computed for the small flagellate Cafeteria roenbegensis from data in Fenchel \& Blackburn (1999; $\left.V_{\text {prey }} \approx 100 \mu \mathrm{m} \mathrm{s}^{-1}, t \approx 2 \mathrm{~s}\right)$, the estimated clearance rate for Oncaea mediterranea NV is $0.2 \mathrm{ml} \mathrm{d}^{-1}$, which is similar to that observed for $O$. mediterranea NV feeding on motile prey (Paffenhöfer 1993). Prey cells with other diffusivities would be cleared at different rates (Fig. 10), but the example illustrates that prey motility governs the clearance rate. That these rare jumpers in fact depend on motile food agrees with observations. For example, jumping late nauplii of Centropages velificatus and O. mediterranea moving 8.5 and $1.9 \%$ of the time (Table 4) require motile prey to support growth (Paffenhöfer et al. 1996). Similarly, cyclopoid and other poecilostomid nauplii, that are all rare jumpers, have been cultured more successfully on a variety of flagellates and dinoflagellates than on diatoms (Gerritsen 1978, Uchima 1979, Uchima \& Hirano 1986, Ferrari \& Ambler 1992, Paffenhöfer 1993, Sabatini \& Kiørboe 1994).

Diffusive transport of prey towards the predator occurs at a high rate immediately after the nauplius has jumped to a new spot and then declines asymptotically towards a steady state rate as the nauplius remains at that spot (Eq. 6b). Jumping nauplii may utilize the initially high, unsteady diffusion by jumping frequently. However, with increasing jump frequency, the nauplius spends an increasing fraction of its time in jumps, leaving a decreasing fraction of time for collecting food (the $1-\alpha f$ term in Eq. 6c declines). The second implication of Eq. (6) is, therefore, that there exists an optimal jump frequency where the potential clearance rate due to diffusion peaks. The optimum is close to 3 jumps $\mathrm{s}^{-1}$ (Fig. 10), and this estimate is largely independent of the magnitude of $R$ and the diffusivity of the prey (e.g. between 2.5 and $3.2 \mathrm{~s}^{-1}$ for $D$ between $10^{-4}$ and $10^{-6} \mathrm{~cm}^{2} \mathrm{~s}^{-1}$ ). The jump frequency of late stage Acartia tonsa is close to the optimum frequency, suggesting that these nauplii relocate at this frequency to optimize diffusive delivery of prey particles.

\section{CONCLUSION}

In ecological considerations, nauplii are often assumed to be a homogenous group; however, here, we show that the different species and also different stages of the same species have characteristic motility behaviors that differ markedly from one another. If to be generalised, naupliar motility can be split into a jump-sink type of behavior (of different frequencies ranging from $1 \mathrm{~min}^{-1}$ to $3 \mathrm{~s}^{-1}$ ) and smooth swimming (with or without intermittent periods of sinking). Simple encounter models suggest that the motility of all types of nauplii can account for their encounter with food, but through different mechanisms. Slow, more or less continuously swimming nauplii rely on their low but persistent motility for food encounter when they scavenge through the water. Such behavior is displayed by most late-stage calanoid nauplii, and results in high encounter volumes and allows for some capture inefficiency. For nauplii with a jump-sink behavior, there seem to be 2 extreme foraging strategies: (1) rare jumpers, represented by all cyclopoid and poecilostomatoid nauplii, where jumps presumably mainly help compensate for sinking and encounters with food depend on motility of the prey; and (2) frequent jumpers, such as late Acartia tonsa, where jumps help to avoid local food depletion. Most young calanoid nauplii display jump-sink behavior with intermediate jump frequencies that are substantially lower than the predicted frequency for optimal prey encounter. However, in contrast to cyclopoid and poecilostomatoid nauplii, which feed already at Stage NI (Ferrarri \& Ambler 1992), most calanoids do not commence feeding until NII or NIII (Mauchline 1998). Hence, this behavior may solely need to be understood in terms of predator avoidance.

The costs of a high jump frequency are 2-fold, viz. a significant metabolic prize (cf. above), and, presumably, an increased susceptibility to predators. In general, motility behavior represents a trade-off between finding food and avoiding being encountered and eaten by a predator. Everything else being equal, high motility implies both high food encounter rates and high risk of encountering a predator. The motility behavior of nauplii-or any other organism - can therefore not be fully understood without taking predator avoidance capabilities into account (Titelman \& Kiørboe 2003).

Acknowledgements. Uffe Thygesen wrote the code used for the motility calculations, Jack Melbye and Malene Carlsen maintained phytoplankton cultures, Enric Saiz supplied the Euterpina and Sandra Green the Eurytemora, which were used to start copepod cultures. Comments from Andy Visser, Peter Tiselius, Marku Viitasalo and Peter Jumars improved the paper. This study was funded by a EU-TMR Marie Curie PhD Fellowship (ERBFMBICT 972833) to J.T. and a grant (9801391) from the Danish Natural Science Research Council to T.K. 


\section{LITERATURE CITED}

Berg HC (1993) Random walks in biology. Princeton University Press, Princeton, NJ

Berggreen U, Hansen B, Kiørboe T (1988) Food size spectra, ingestion and growth of the copepod Acartia tonsa during development: implications for determination of copepod production. Mar Biol 99:341-352

Björnberg TKS (1972) Developmental stages of some tropical and subtropical planktonic marine copepods. Stud Fauna Curaçao Other Caribb Isl 40:1-180

Björnberg TKS (1986a) Aspects of the appendages in development. Syllogeus 58:51-66

Björnberg TKS (1986b) The rejected nauplius. Syllogeus 58: $232-236$

Bresciani J (1960) Some features of the larval development of Stenhelia (Delavalia) paulustris Brady 1868 (Copepoda, Harpacticoida). Vid Medd Dan Naturhis Foren 123: 237-247

Buskey EJ (1994) Factors affecting feeding selectivity of visual predators on the copepod Acartia tonsa: locomotion, visibility and escape responses. Hydrobiologia 292/293: 447-453

Buskey EJ, Coulter C, Strom S (1993) Locomotory patterns of microzooplankton: potential effects on food selectivity of larval fish. Bull Mar Sci 53:29-43

Fenchel T, Blackburn N (1999) Motile chemosensory behaviour of phagotrophic protists: mechanisms for and efficiency in congregating at food patches. Protist 150:325-336

Ferrarri FD, JW Ambler (1992) Nauplii and copepodids of the cyclopoid copepod Dioithona oculata (Farran, 1913) (Oithonidae) from a mangrove cay in Belize. Proc Biol Soc Wash 105:275-298

Gauld DT (1958) Swimming and feeding in crustacean larvae: the nauplius larvae. Proc Zool Soc Lond 132:31-51

Gerritsen J (1978) Instar-specific swimming patterns and predation of planktonic copepods. Verh Int Verein Limnol 20: 2531-2536

Harris RP, Paffenhöfer GA (1976) Feeding growth and reproduction of the marine copepod Temora longicornis Müller. J Mar Biol Assoc UK 56:675-690

Hay SJ, Kiørboe T, Matthews A (1991) Zooplankton biomass and production in the North Sea during the autumn circulation experiment, October 1987-March 1988. Cont Shelf Res 11:1453-1476

Heinle DR, Flemer DA (1975) Carbon requirements of a population of the estuarine copepod Eurytemora affinis. Mar Biol 31:235-247

Huys R, Boxshall GA (1991) Copepod evolution. The Ray Society, Vol 159. Natural History Museum, London, p 468

Kiørboe T (1997) Small-scale turbulence, marine snow formation, and planktivorous feeding. Sci Mar 61(Suppl 1): 141-158

Kiørboe T, Sabatini M (1995) Scaling of fecundity, growth and development in marine planktonic copepods. Mar Ecol Prog Ser 120:285-298

Kiørboe T, Titelman J (1998) Feeding, prey selection and prey encounter mechanisms in the heterotrophic dinoflagellate Noctiluca scintillans. J Plankton Res 20:1615-1636

Editorial responsibility: Otto Kinne (Editor), Oldendorf/Luhe, Germany
Kiørboe T, Møhlenberg F, Hamburger K (1985) Bioenergetics of the planktonic copepod Acartia tonsa: relation between feeding, egg production and respiration, and composition of specific dynamic action. Mar Ecol Prog Ser 26:85-97

Klein-Breteler WCM, Fransz HG, Gonzales SR (1982) Growth and development of 4 calanoid copepod species under experimental and natural conditions. Neth J Sea Res 16: 195-207

Landry MR, Fagerness VL (1988) Behavioral and morphological influences on predatory interactions among marine copepods. Bull Mar Sci 43:509-529

Mauchline J (1998) The biology of calanoid copepods. In: Blaxer JHS, Southward AJ, Tyler PA (eds) Advances in Marine Biology, Vol 33. Academic Press, San Diego, CA

Osborn T (1996) The role of turbulent diffusion for copepods with feeding currents. J Plankton Res 18:185-195

Paffenhöfer GA (1971) Grazing and ingestion of nauplii, copepodids and adults of the marine planktonic copepod Calanus helgolandicus. Mar Biol 11:286-298

Paffenhöfer GA (1993) On the ecology of marine cyclopoid copepods (Crustacea, Copepoda). J Plankton Res 15: $37-55$

Paffenhöfer GA (1998) On the relation of structure, perception and activity in marine planktonic copepods. J Mar Syst 15:457-473

Paffenhöfer GA, Harris RP (1976) Feeding, growth and reproduction of the marine planktonic copepod Pseudocalanus elongatus Boeck. J Mar Biol Assoc UK 56:327-344

Paffenhöfer GA, Lewis KD (1989) Feeding behavior of the nauplii of the genus Eucalanus (Copepoda, Calanoida). Mar Ecol Prog Ser 57:129-136

Paffenhöfer GA, Strickler JR, Lewis KD, Richman S (1996) Motion behavior of early copepodid stages of marine and planktonic copepods. J Plankton Res 18:1699-1715

Sabatini M, Kiørboe T (1994) Egg production, growth and development of the cyclopoid copepod Oithona similis. J Plankton Res 16:1329-1351

Storch O (1928) Der Nahrungserwerb zweier Copepodennauplien (Diaptomus gracilis und Cyclops strenus). Zool Jahrb Abt Allg Zool Physiol Tiere 45:385-436

Støttrup JG, Richardson K, Kirkegaard E, Pihl NJ (1986) The cultivation of Acartia tonsa Dana for use as live food source for marine fish larvae. Aquaculture 52:87-96

Titelman J (2001) Swimming and escape behavior of copepod nauplii: implications for predator-prey interactions among copepods. Mar Ecol Prog Ser 213:203-213

Titelman J, Kiørboe T (2003) Predator avoidance by nauplii. Mar Ecol Prog Ser 247:137-149

Uchima M (1979) Morphological observation of developmental stages in Oithona brevicornis (Copepoda, Cyclopoida). Bull Plankton Soc Jpn 26:59-76

Uchima M, Hirano R (1986) Food of Oithona davisae (Copepoda: Cyclopoida) and the effect of food concentration at first feeding on the larval growth. Bull Plankton Soc Jpn 33:21-28

van Duren LA, Videler JJ (1995) Swimming behavior of developmental stages of the calanoid copepod Temora longicornis at different food concentrations. Mar Ecol Prog Ser 126:153-161

Submitted: April 29, 2002; Accepted: September 10, 2002 Proofs received from author(s): January 6, 2003 